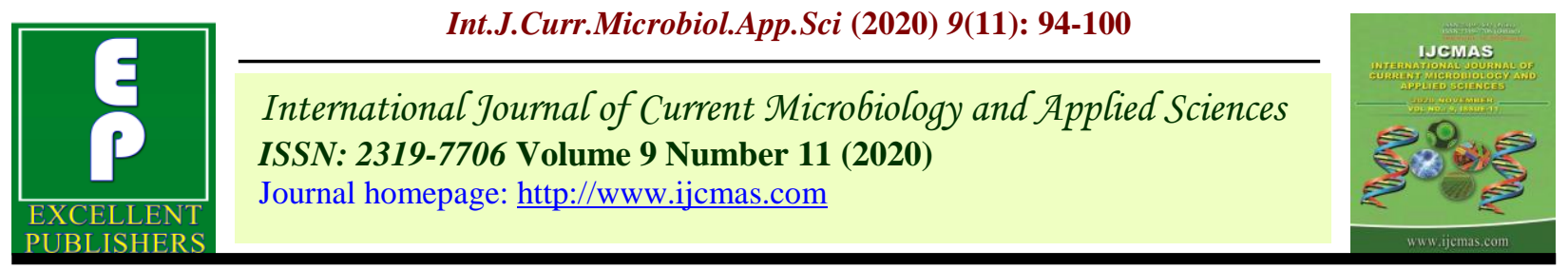

Original Research Article

https://doi.org/10.20546/ijcmas.2020.911.010

\title{
Identification of QTLs and Markers Linked to Root Traits in Rice (Oryza sativa L.)
}

\author{
Sahoo Abinita ${ }^{1}$, R. Gudadhe Kalyani ${ }^{1}$, Sunil K. Verma ${ }^{2}$, Ritu R. Saxena ${ }^{2}$, \\ Satish B. Verulkar ${ }^{1}$ and Ambika Prasad Mishra ${ }^{3 *}$
}

${ }^{1}$ Department of Plant Molecular Biology and Biotechnology, ${ }^{2}$ Genetics and Plant Breeding, Indira Gandhi Krishi Vishwavidyalaya, Raipur (C. G. ), India

${ }^{3}$ Department of SoilScience \& Agricultural Chemistry, Odisha University of Agriculture \& Technoly, India

*Corresponding author

\section{A B S T R A C T}

\section{Keywords}

Rice, Root traits,

QTL, Markers

Article Info

Accepted:

04 October 2020

Available Online:

10 November 2020
Root is an important plant part mainly responsible for absorption of water and nutrient, and hence root traits affect the plant growth and development under normal as well as under water stress and nutrient stresses. A RIL population consisting of 116 lines developed using a land race with deep and thick root was grown in mini-rhizotron for measuring root volume and root length. The genotypic data of this population was also developed using SSR markers. The QTL analysis leads to the identification of twenty four QTLs for root length and three QTLs for root volume, the markers linked to these traits were also identified.

\section{Introduction}

Rice (Oryza sativa L.) is the world's most important wetland food crop. Large areas of rice are grown under lowland and upland rainfed conditions. Compare to other cereals, rice requires more water. Drought is one of the most important and highly unpredictable abiotic stresses causing drastic reductions in yield under rainfed rice environments, affecting $20 \%$ of the total rice growing area in Asia (Pandey and Bhandari, 2008). Root systems form one of the important components of drought resistance. Therefore, improving our understanding of the interaction between root function and drought in rice could have a significant impact on global food security (Gowda et al., 2011).

Root systems influence the amount of water available to the crop depending on their distribution in the soil (Hemamalini et al., 2000). Every plant part has unique functions. Root has a large range of functions, including acquisition of water and nutrients, as well as structural support (Rebouillat et al., 2009). It is also the site of major hormone biosynthesis (Courtosis et al., 2009). Root length and 
surface area are important indicators for a potential uptake of water and nutrients. Root volume indicates that a plant can permeate a particular volume of soil or that it has a proportion of thick or thin roots. Such a plant would have greater water gathering potential for growth and survival (Zurio-Altoveros et al., 1990).

QTL mapping provides a powerful tool for conducting physiological and genetical research to understand and possibly improve drought resistance. It eases screening for traits that are difficult to quantify and influence by environmental stimuli (Hanson et al., 1990). DNA markers have been successfully used for screening plant genomes for quantitative trait loci (QTLs) controlling complex traits, including tolerance to abiotic stresses (Ribaut et al., 1997; Zhang et al., 2001). Development of various types of DNA markers by different techniques has provided a new platform for rice genome research. Among the various types of markers available for genetic mapping, SSR has number of advantages over others. They are highly polymorphic, single locus, co-dominant and multi-allelic (Temnykh et al., 2000). Considering the importance of root traits, this study was undertaken with the major objectives to develop precise phenotypic data and identity the QTLs for these traits.

\section{Materials and Methods}

\section{Plant material}

Recombinant inbred line population in $F_{13}$ generation having 116 lines were developed from a cross between Danteshwari and Dagad Deshi. Danteshwari is high yielding variety and moderately susceptible to water stress condition while Dagad Deshia local land race is tolerant to water stress condition with deep and thick root system.

\section{Phenotyping}

The plant material was grown in minirhizotron (soiled filled in between two glassplates of 1'x1.5') at University Research and Instructional farm, Indira Gandhi Krishi Vishwavidyalaya, Raipur (C.G.) during the month of December to January to generate the phenotypic data. In each glass rhizotron three seeds were sown, later thinned to two when they emerged. Proper watering was done up to 60 days. After 60 days the glass plates were opened, soil removed carefully in water to get the intact root. The root was then again washed with water. The root was then scanned with root scanner to record total root length and root volume. It was done with the help of software WinRhizo root scanner.

\section{Genotyping}

DNA from 116 RILs along with parents was isolated using mini prep method (Doyle and Doyle, 1987). Each DNA samples were quantified on Nano Drop Spectrophotoscopy and diluted to $40 \eta \mathrm{g} / \mu \mathrm{l}$. SSR and HvSSR primers were used for genotyping of this whole population. For DNA amplification, reaction mixture as given in table 1 was used and temperature profile as elaborated in table 2 was used for PCR amplification in an Applied Biosystem PCR machine. To each amplified PCR product, $3 \mu$ of loading dye was added and then electrophoresed in 5\% PAGE. After electrophoresis gels were stained with Ethidium Bromide for 5 minutes, washed with distilled water and photographed using gel doc unit (BIO RAD).

\section{Results and Discussion}

The different RIL lines along with parents exhibited significant variation for both the parameters i.e. root length and root volume. The lines with higher and lower root length and root volume are presented in table $3 \& 4$ 
respectively. The variation in the RIL population was expected as both the parents involved in the cross are different for these two traits. High root volume indicate that a plant can permeate a large volume of soil or that it has a high proportion of thick roots, such plants would have greater water gathering potential for growth and survival. The drought tolerant varieties having greater root volume than drought susceptible varieties (Zurio-Altoveros et al., 1990). Verma 2014, reported that the root studies using minirhizotron has significant correlation with performance of individual line under water stress condition. Similarly Price et al., 2012 has also reported the utility of this type of morphological studies in understanding the rooting pattern (Table 5 and 6).

Table.1 PCR mixture for one reaction

\begin{tabular}{|l|c|c|}
\hline Reagent & Stock concentration & Volume $(\boldsymbol{\mu l})$ \\
\hline Sterile and nanopure $\mathbf{H}_{\mathbf{2}} \mathbf{O}$ & - & 13.5 \\
\hline PCR buffer & $10 \mathrm{X}$ & 2.0 \\
\hline dNTPs (Mix) & $1 \mathrm{mM}$ & 1.0 \\
\hline Primer (reverse and forward) & $5 \mathrm{pM}$ & 1.0 \\
\hline Taq polymerase & $1 \mathrm{unit} / \mu \mathrm{l}$ & 0.5 \\
\hline DNA template & $40 \mathrm{\eta g} / \mu \mathrm{l}$ & 2.0 \\
\hline Total & & 20.0 \\
\hline
\end{tabular}

Table.2 Temperature profile used for PCR amplification using microsatellite markers

\begin{tabular}{|c|c|c|c|c|}
\hline Steps & Temperature $\left({ }^{\circ} \mathrm{C}\right)$ & Duration (min.) & Cycles & Activity \\
\hline 1 & 95 & 5 & 1 & Denaturation \\
\hline 2 & 94 & 1 & & Denaturation \\
\hline 3 & 55 & 1 & 34 & Annealing \\
\hline 4 & 72 & 2 & & Extension \\
\hline 5 & 72 & 10 & $\mathbf{1}$ & Final Extension \\
\hline 6 & 4 & 24 hrs & 1 & Storage \\
\hline
\end{tabular}

Table.3 Lines with high and low root volume

\begin{tabular}{|l|c|c|c|c|}
\hline \multirow{2}{*}{ S. No. } & \multicolumn{2}{|c|}{ High root volume } & \multicolumn{2}{c|}{ Low root volume } \\
\cline { 2 - 5 } & Line No. & Root volume $\left.\mathbf{( c m}^{\mathbf{3}}\right)$ & Line No. & Root volume $\left.\mathbf{( c m}^{\mathbf{3}}\right)$ \\
\hline $\mathbf{1}$ & 31 & 0.65 & 1 & 0.37 \\
\hline $\mathbf{2}$ & 50 & 0.61 & 30 & 0.34 \\
\hline $\mathbf{3}$ & 53 & 0.87 & 33 & 0.34 \\
\hline $\mathbf{4}$ & 58 & 0.70 & 46 & 0.19 \\
\hline $\mathbf{5}$ & 60 & 0.73 & 71 & 0.17 \\
\hline $\mathbf{6}$ & 61 & 0.73 & 73 & 0.20 \\
\hline $\mathbf{7}$ & 77 & 0.60 & 81 & 0.13 \\
\hline $\mathbf{8}$ & 99 & 0.59 & 85 & 0.30 \\
\hline $\mathbf{9}$ & 106 & 0.61 & 101 & 0.16 \\
\hline $\mathbf{1 0}$ & 108 & 0.66 & 107 & 0.03 \\
\hline
\end{tabular}


Table.4 Lines with high and low root length

\begin{tabular}{|l|c|c|c|c|}
\hline \multirow{2}{*}{ S. No. } & \multicolumn{2}{|c|}{ High root length } & \multicolumn{2}{c|}{ Low root length } \\
\cline { 2 - 5 } & Line No. & Root length $\mathbf{( c m )}$ & Line No. & Root length $\mathbf{( c m )}$ \\
\hline $\mathbf{1}$ & 98 & 462.99 & 88 & 336.78 \\
\hline $\mathbf{2}$ & 56 & 455.84 & 66 & 376.74 \\
\hline $\mathbf{3}$ & 99 & 454.89 & 71 & 386.90 \\
\hline $\mathbf{4}$ & 41 & 452.63 & 107 & 389.36 \\
\hline $\mathbf{5}$ & 58 & 451.34 & 85 & 389.69 \\
\hline $\mathbf{6}$ & 26 & 447.49 & 31 & 390.45 \\
\hline $\mathbf{7}$ & 106 & 446.54 & 62 & 392.79 \\
\hline $\mathbf{8}$ & 50 & 446.07 & 81 & 396.98 \\
\hline $\mathbf{9}$ & 30 & 443.19 & 46 & 399.16 \\
\hline $\mathbf{1 0}$ & 52 & 437.09 & 44 & 403.16 \\
\hline
\end{tabular}

Table.5 List of QTLs identified for root length through scanning under mini-rhizotron condition

\begin{tabular}{|c|c|c|c|c|}
\hline Chromosome no. & Left Primers & Right primers & LOD Value & Phenotypic variance \% \\
\hline C2 & RM-492 & RM-475 & 4.4 & 5.106 \\
\hline C2 & HvSSR2-78 & RM-6375 & 4.0 & 1.6512 \\
\hline C3 & RM-411 & RM-85 & 3.9 & 0.5994 \\
\hline C4 & HvSSR4-42 & RM-564 & 4.3 & 2.082 \\
\hline C7 & RM-348 & RM-559 & 3.1 & 1.0838 \\
\hline C11 & RM-481 & HvSSR7-40 & 4.0 & 0.0158 \\
\hline
\end{tabular}

Table.6 List of QTLs identified for root length through scanning under mini-rhizotron condition

\begin{tabular}{|c|c|c|c|c|}
\hline Chromosome & Left primer & Right primer & $\begin{array}{c}\text { LOD } \\
\text { value }\end{array}$ & $\begin{array}{c}\text { \% phenotypic } \\
\text { variance }\end{array}$ \\
\hline $\mathbf{1}$ & RM 8071 & RM 259 & 2.5 & 0.424 \\
\hline $\mathbf{2}$ & RM 492 & RM 475 & 3.0 & 2.296 \\
\hline $\mathbf{2}$ & RM 109 & HvSSR2-12 & 2.6 & 1.053 \\
\hline
\end{tabular}

Fig.1 Genetic map locating three QTLs for root length under mini-rhizotron on $\mathrm{C} \# 2,3,4,7,11$ by QTL cartographer 2.5

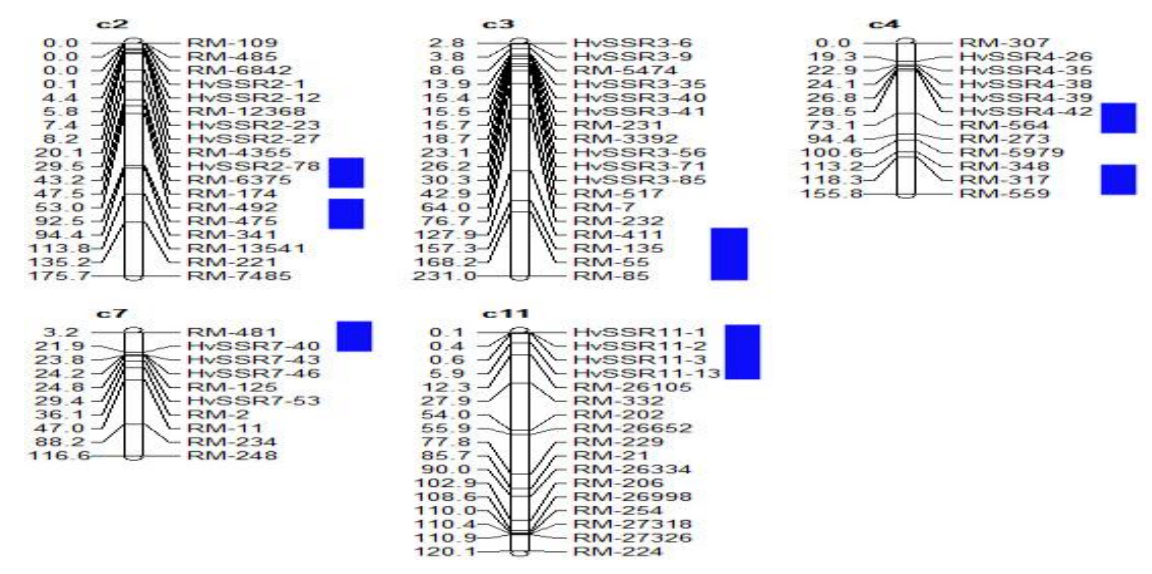


Fig.2 Genetic map locating three QTLs for root volume under mini-rhizotron on C \#1 and C \#2 by QTL cartographer 2.5

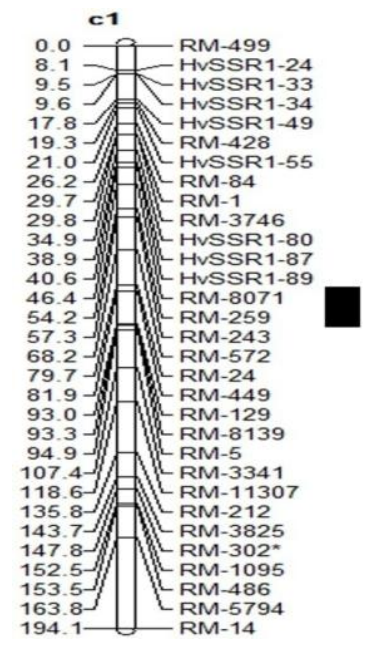

The DNA of 116 recombinant inbred lines along with the parents was subjected to PCR based simple sequence repeat (SSR) technique to generate genotypic data using rice SSR primers. The markers were taken from previously published rice genetic and sequence map (Singh et al., 2009; McCouch et al., 2002 and Temnykh et al., 2001).

The phenotypic data along with genotypic data of 192 SSR and HvSSR marker was then used for QTL analysis using QTL Cartographer 2.5. Three QTLs were identified for root volume and 24 QTLs for root length. The result of QTL analysis is presented in figure 1 and 2 . The perusal of figure 1 indicate that the identification of three QTLs for root volume which were located between RM 8071 to RM 259 on chromosome \#1, with LOD score of 2.5, another QTL was present between RM 492 to RM 475 on chromosome \#2 with LOD score of 3.0 and the next QTL was present between RM 109 to HvSSR2-12 on same chromosome \#2 with LOD score of 2.6. Hemamalini et al., (1990) identified two QTLs associated with root volume on chromosome 2 and 3 namely qRTV2-1 and qRTV3-1 respectively which shows the response at low moisture stress. Similarly for

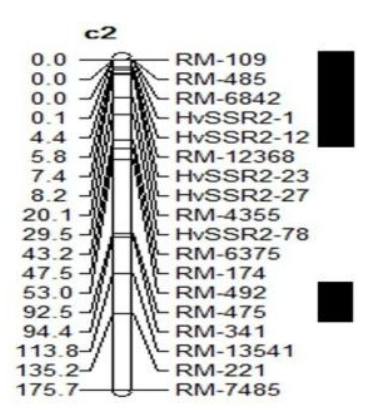

root length QTLs were detected on chromosome 5 between RM 163 and RM 440; chromosome 6 between HvSSR 6-35 and HvSSR 6-44 with good LOD score of 5 or above was associated with root traits i.e., total root length, and average root diameter (Verma 2014). QTL for root length on chromosome 6 (qRL 6.1) was also reported by Obara et al., 2010. QTL for average diameter on chromosome 12 between HvSSR 12-51 to RM 277 was also associated with QTL for grain yield under rainfed condition. Root traits showed positive significant correlation under rainfed condition, so there QTL play role in water uptake. Bernier et al., (2009a) reported qtl12.1 on chromosome 12 which increase water uptake under upland condition. These QTLs affecting root length and root volume will be very useful in breeding program for developing high yielding drought tolerant rice varieties.

\section{Acknowledgement}

We are thankful to Department of Plant Molecular Biology and Biotechnology, Indira Gandhi Krishi Vishwavidyalaya for providing financial assistance and laboratory to carry out this work. 


\section{References}

Bernier, J., Kumar, A., Ramiah, V., Spaner, D. and Atlin, G. 2007.A large effect of QTL for grain yield under reproductive stage drought stress in upland rice. Crop Sci., 47: 505-518.

Cai, J., Zhang, X., Wang, B., Yan, M., Qi, Y. and Kong, L. 2011. A genetic analysis of segregation distortion revealed by molecular markers in Lophopyrum ponticum chromosome 7E.J. Genet., 90(2): 373-376.

Causse, M., Fulton, T.M., Cho, Y.G., Ahn, S.N., Wu, K., Xiao, J., Chunwongse, J., Yu, Z., Ronald, P.C., Harrington, S.B., Second, G.A., McCouch, S.R. and Tanksley, S.D. 1994. Saturated molecular map of the rice genome based on an interspecific backcross population. Genetics., 138: 1251-1274.

Courtosis, B., Ahmadi, N., Khowaja, F., Price, A.H., Rami, F.J., Frouin, J., Hamelin, C. and Ruiz, M. 2009. Rice root genetic architecture: Meta analysis from a drought QTL database. Rice., 2: 115-128.

Doyle, J.J. and Doyle, J.L. 1987. A rapid DNA isolation procedure for small quantities of fresh leaf tissue. Phytochem. Bull., 19: 11-15.

Gowda, V.R.P., Henry, A., Yamauchi, A., Shashidhar, H.E., Serraj, R., 2011. Root biology and genetic improvement for drought avoidance in rice. Field Crop Res., 122(1): 1-13.

Hemamalini, G.S., Shashidhar, H.E., and Hittalmani, S. 2000. Molecular marker assisted tagging of morphological and physiological traits under two contrasting moisture regimes at peak vegetative stage in rice (Oryza sativa L.). Euphytica, 112: 69-78.

McCouch S.R., Teytelman L., Xu Y., Lobos K.B., Clare K., Walton M., Fu B., et al., 2002. Development and mapping of
2240 new SSR markers for rice.DNA Res., 9: 199-207.

Pandey, S. And Bhandari, H. 2008. Drought: economics costs and research implications. In: Serraj R., Bennet, J. and Hardy, B. (Eds.), Drought Frontiers in Rice: Crop Improvement for Increased Rainfed Production. World Scientific Publishing and Los Banos (Philippines): International Rice Research Institute, Singapore. Pp. 3-17.

Rebouillat, J., Dievart, A., Verdeil, J.L., Escoute, J., Giese, G., Breitler, J.C., Gantet, P., Espeout, S., Guiderdoni, E., Perin, C., 2009. Molecular genetics of rice root development. Rice, 2: 15-34.

Ribaut, J.M., Jiang, C., Gonzalez-de-Leon, D., Edmeades, G.O. and Hoisington, D.A. 1997. Identification of quantitative trait loci under drought conditions in tropical maize. Yield components and marker-assisted selection strategies. Theor. Appl. Genet., 94: 887-896.

Singh, H., Deshmukh, R.K., Singh, A., Singh, A.K., Gaikwad, K., Gaikwad, T., Sharma, T.R., Mohapatra, T. And Singh, N.K. 2009. Highly variable SSR markers suitable for rice genotyping using Agarose gels. Mol. Breed., 25(2): 359-364.

Shashidhar, H.E., Vinod, M.S., Naveen, S., Sharma, G.V. and Krishnamurthy, K. 2005. Markers linked to grain yield using bulked segregant analysis approach in rice (Oryza sativa L.). Rice Genet. Newsl., 22: 69-71.

Temnykh, S., Park, W.D., Ayres, N., Contrihour, S., Hauck, N., Liponich, L., Cho, Y.G., Ishii, T., and McCouch, S.R. 2000. Mapping and genome organization of microsatellite sequence in rice (Oryza sativa L). Theor. Appl. Genet., 100(5): 697-712.

Xiao, J., Li, J., Yuan, L. and Tanksley, S.D. 1996. Identification of QTLs affecting traits of agronomic importance in 
recombinant inbred population derived from a subspecific cross. Theor. Appl. Genet., 92: 230-244.

Xu, Y., Zhu, L., Xiao, J., Huang, N. and McCouch, S.R. 1997. Chromosomal regions associated with segregation distortion of molecular markers in $F_{2}$ backcross double haploid and recombinant inbred population in rice (Oryza sativa L.). Mol. Gen. Genet., 253: 535-545.

Zhang, J., Zheng, H.G., Aarti, A., Pantuman, G., Nguyen, T.T., Tripathy, J.N., Sarial,
A.K., Robin, S., Badu, R.C, Nguyen, B.D, Sarkarung, S., Blum, A., Nguyen, H.T. 2001. Locating genomic regions associated with components of drought resistance in rice: comparative mapping within and across species. TheorAppl Genet, 103: 19-29.

Zurio-Altoveros, C., Loresto, G.C., Obiem, M. and Chang T.T. 1990. Differences in Root volume of selected upland and lowland rice varieties. International Rice Research Newsletter, 15(2): pp8.

\section{How to cite this article:}

Sahoo Abinita, R. Gudadhe Kalyani, Sunil K. Verma, Ritu R. Saxena, Satish B. Verulkar and Ambika Prasad Mishra. 2020. Identification of QTLs and Markers Linked to Root Traits in Rice (Oryza sativa L.). Int.J.Curr.Microbiol.App.Sci. 9(11): 94-100. doi: https://doi.org/10.20546/ijcmas.2020.911.010 